\title{
Studies on the Detoxicating Hormone of the Liver (Yakriton).
}

\author{
6th Report.1)
}

Proposal of Quantitative ${ }^{2)}$ Estimation of Hunger Injury.

By

\author{
AKIRA SATO. \\ (传藤 彰) \\ (From the Pediatric Department, Faculty of Jedicine, Tohohu \\ Imperial University, Sendai. Director, Prof. A. Sato.)
}

It is a matter of course that a strong child is stronger than a weak one and that one child after one day's fasting is stronger than the same child after two days' fasting. But which is the stronger of the two, a strong child fasting or a weak one not fasting? The comparison is impossible. Now I propose a method of quantitative estimation of starvation, by which the grade of injury done by hunger to an organism may be expressed in figures, so that a direct comparison between the two different states may become possible.

\section{Questions which Led to Device of the Method.}

According to the detoxicating liver power, ${ }^{3)}$ all rabbits are divided into more than the 6 classes, viz. $a, b, c, d, e$ and $f$. For the sake of simplicity we will confine ourselves to animals of $b$ and $f$ class, because most rabbits or rabbits of normal liver power belong to class $b$; and $f$ (class, to which

1) Read at the 32nd Annual Meeting of the Japanese Pediatric Society held in Kyoto, 1927, April.

2) Quantitative estimation of hunger injury= not "quantitative estimation of some chemical constituents of the body during hunger," but "quantitative determination of hunger injury itself."

3) A. Sato and H. Sakurada, Third Report, Tohoku J. Exp. Med., 1927, 8, 847.

4) As far as fresh animals are concerned, my experience has thus far shown that a bealthy looking animal may be of class $a$ or of class $f^{5}(\mathrm{R} /)^{5}=$ rabbit which remains quite unaffected in spite of $3 \%$ ammonium chloride injection in an amount of $5 \times 10$ c.c. per kilogram of body weight. $R f^{\prime}=R f=$ rabbit quite unaffected in spite of $1 \times 10$ c.c.) There may be fresh animals of class $f^{6}$ or $f^{f}$, only $I$ bave not yet tried larger amounts than $5 \times 10$ c.c. of the ammonium solution. 
only a few rabbits belong, is of very active liver power.

The distance between class $f$ and class $b$ is measurable-so to speakwith a scale, i. e. with Iakiton scale, because $10 \mathrm{R}$. A. U. (1) (10 rabbitammonia-units) of yakriton (per kilogram of body weight) will instantly promote a rabbit of $b$ to class $f$. The distance in question is thus $10 \mathrm{R} . \mathrm{A}$. U. of yakriton.

Now, if a rabbit' of class. $f(\mathrm{R} f)$ is starved for some time, it becomes of class $b$ (as will be shown in Table I). But it docs not come down to class $a$, if it is starved for some time longer, but remains in the same class b. Thus it will appear that a $R f$, if starved for some time, comes down by $10 \mathrm{R}$. A. U. to class $b$ and remains stationary thereafter in the same class, even if the starvation is still prolonged, as far as the detoxicating liver power is concerned. This fact is contrary to our expectation, because prolonged fasting must of course lower the detoxicating activity. This was my first question.

\section{Table I.}

Liver test of rabbits of class $f$ made to fast.

\begin{tabular}{|c|c|c|c|c|c|c|c|c|c|c|c|c|c|c|}
\hline Days of feeding & & 8 & & \begin{tabular}{l|l}
3 & 3
\end{tabular} & & 10 & & 5 & & \begin{tabular}{l|l}
3 & 12
\end{tabular} & & 6 & 3 & \\
\hline Days of hunger & 4 & & 3 & & 3 & & 3 & & 3 & & 4 & & & \\
\hline No. $1369, \mathrm{R} f$ & $b$ & $f$ & $b$ & $d \cdots f$ & $c$ & $f$ & $d$ & $f$ & $c$ & $e_{1}^{1} f$ & $c$ & $d \cdots$ & $a_{\dagger}^{\dagger}$ & \\
\hline No. $1370, \mathrm{R} f$ & $b$ & $f$ & $b$ & $b \cdots c$ & $b \dagger$ & & & & & & & & & \\
\hline & & & & 1371 , & & $f$ & $b$ & $f$ & $b$ & $b \underset{\mid}{\mid}$ & $c$ & $d \cdots$ & $f \quad b$ & $\left\{\begin{array}{c}\text { †next } \\
\text { day }\end{array}\right\}$ \\
\hline
\end{tabular}

$\dagger \ldots .$. died (during the test, unless otherwise explained).

What will become of a rabbit of class $b(\mathbf{R} b)$ ? If it is starved, it does not degenerate into the lower class $a$, but stays in the same class $b$, even though the fasting is more prolonged. It will then appear that a $\mathrm{R} b$ will retain the same detoxicating power while fasting as when feed. This is again contrary to our expectation. This was my second question.

1) A. Sato, Fourth Report, Tohoku J. Exp. Med., 1927, 8, 353.

2) Rf does not mean a fresh rabbit of class $f$, but $R$......ffff, as already explained in the Third Report. Of course R....ffeffef....., that is, $\mathbf{R}$ (average $f$ ) may be meant too.

3) $\mathrm{R} b$ means $\mathrm{R} \ldots \ldots b b b d b$, or $\mathrm{R} \ldots \ldots b c b b c b b \ldots . . .($ average $b$ ). 
If $a \mathrm{R} b$ is fed again, it remains $\mathrm{R} b$; this is no absurdity now that we have learned the above mentioned fact. But if a $\mathrm{R} f$, which has become $\mathrm{R} b$ when fasting, is fed again, it remains $\mathrm{R} b$ for some long time, but attains the original class $f$ at last (Table I). It will thus appear that a $\mathrm{R} f$ will change its detoxicating power when fasting, while a $\mathrm{R} b$ will always retain the same detoxicating power when fed as well as while fasting. This is absurd and thus arose my third question.

The following table (Table II) will show the relation above mentioned simply.

\section{TABILE II.}

Liver tests of rabbits of class $f$ and class $b$ when fed and while fusting, diagrammatically shown.

\begin{tabular}{|c|c|c|c|c|c|c|c|c|c|c|c|c|c|c|c|c|}
\hline \multirow[b]{2}{*}{$\mathrm{R} \ldots \ldots f f f$} & (when fed & $f$ & $f$ & $f$ & $f$ & $f$ & $f$ & $f$ & $f$ & $f$ & $f$ & $f$ & $f$ & $f$ & $f$ & $f$ \\
\hline & when fasting & $d$ & $c$ & $b$ & $b$ & $b$ & $b$ & $b$ & $b$ & $\begin{array}{l}\text { when } \\
\text { fed } \\
\text { again }\end{array}$ & $b^{1 i}$ & $b$ & $d$ & $f$ & $f$ & $f$ \\
\hline \multirow{2}{*}{ R.....bbb } & (when fed & $b$ & $b$ & $b$ & 6 & $b$ & $b$ & $b$ & $b$ & $b$ & $b$ & $b$ & $b$ & $b$ & $b$ & $b$ \\
\hline & when fusting & $b$ & $b$ & $b$ & $b$ & $b$ & $b$ & $b$ & b) & $\begin{array}{l}\text { when } \\
\text { ded } \\
\text { atritum }\end{array}$ & $b$ & $b$ & $b$ & $b$ & $b$ & $b$ \\
\hline
\end{tabular}

All these questions began, horvever, to be solved when yakriton was used in fasting experiments. As above mentioned, $10 \mathrm{R}$. A. U. of yakriton (per kilogram of body weight) will raise a $\mathrm{R} b$ to a $\mathrm{R} f$, because the distance between $R f$ and $\mathrm{R} b$ is 10 R.A. U. But a $\mathrm{R} b$ while fasting eannot generally be raised up to Rf with 10 R.A.U.: the distance has now become larger." And this distance will become larger and larger, the longer the fasting. That is, a $\mathrm{R} b$ will require more units of yakriton, the more days it is made

1) From Table $I$ it will be seen that the degradation of the detoxicating power caused by hunger will not usually be made good even after 2 or 3 days of feeding.

2) The first hint of the fact was given us in this way: In the course of his study concerning the behaviour of the chlorine in the blood, II. Morishit in our laboratory gave to each of his four rabbits $(R b)$ yakriton in full dosis (10 R. A. U. per kilogram of body weight) and put them to the liver test with the ammonium injection. Our expectation was that each of these animals would of course react like $R f$ on the administration of yakriton, but the results were $f, f, d$ and even $b$ respectively. At that time, a deterioration of yakriton due to bad preservation was, as we presumed, the probable cause, but it soon dawned on us that the ammonium injection made before the morning feeding was most likely the cause of the failure of yakriton to raise the rabbits from $b$ to $f$. (The potency testing of yakriton is to be done always in the afternoon, much later than the morning feeding). 
to fast. Thus it will follow that the amount of yakriton,- the number of R. A. U.- designates the grade of inanition.

The same $R b$ when fed, in one day's fasting and in two days' fasting will show the same detoxicating ability at the liver function test, but if it is attempted to raise the rabbit to class $f$ at the test, then the animal will require only $10 \mathrm{R}$. A. U. of yakriton when fed, while it will require more units when fasting one day, and many more, when fasting two days. The distance from the same class $b$ to the same class $f$ thus varies greatly according to the length of fasting to which an animal has been put.

Now for the $\mathrm{R} f$. A $\mathrm{R} f$ will become $\mathrm{R} b$ when it is made to fast for some time, as stated above. But $10 \mathrm{R}$. A. U. of yakriton will not raise the $\mathrm{R} b$ to the class $f$ to which it has belonged previously and properly (though the distance between $\mathrm{R} f$ and $\mathrm{R} b$ is $10 \mathrm{R}$. A. U. during feeding). The distance is larger, but it is not so large as in the case of $R b$. In other words, if $\mathrm{R} f$ and $\mathrm{R} b$ are starved for the same length of time and though they show the same symptom (viz. of class $b$ ) at the detoxicating liver function test, yet it does not follow that both of them are now of the same detoxicating power, because they can be raised to class $f$ only with different amounts of yakriton; $\mathrm{R} f(\mathrm{R} b$ for the time being) with less units and $\mathrm{R} b$ (to which it properly belongs) with many more units. Thus it will be shown that $\mathrm{R} f$ and $\mathrm{R} b$ are of different liver activities, even when they may in hunger seem to belong to the same class $b$ from the symptoms manifested at the liver function test.

\section{Actual Method of Quantitative Estimation of Hunger Injury.}

A number of rabbits of the same detoxicating class (R.....fff only, or R.....bbb only, for instance) are made to fast for a definite number of days. To different groups of them different numbers of R. A. U. of yakriton are subcutaneously administered, and 5 minutes later the intraperitoneal injection of $3 \% \%$ ammonium chloride solution in an amount of 10 c.c. (per kilogram of body weight) performed. Then Group I will react like $\mathrm{R} f$, Group II like Re, Group III like Rd, Group IV like Re and Group V like $\mathbf{R} b$. Then the number of units of yakriton (per kilogram of body weight) used with the animals of Group II will express the degradation of the detoxicating liver power approximately, so that if in a given experiment $120 \mathrm{R}$. A. U. has raised a group of the animals tested to class $e$, then $120(+\infty)$ R. A. U. will be the required figures. The amount of yakriton which has raised the animals to class $f$ may be either just the sufficient 
amount or too much, so that the units of yakriton which has raised them to class $e$ may better be preferred (with $\alpha$ in addition). See Table III.

\section{TABIAE III.}

Liver test of rabbits of class $f$.

\begin{tabular}{|c|c|c|c|c|}
\hline $\begin{array}{l}\text { No. of rabbits; } \\
\text { class of animals }\end{array}$ & $\begin{array}{l}\text { On the } 4 \text { th } \\
\text { day of } \\
\text { hunger } \\
\text { first } \\
\text { experiment }\end{array}$ & $\begin{array}{l}\text { On the } 5 \text { th } \\
\text { day of } \\
\text { feeding }\end{array}$ & $\begin{array}{l}\text { On the } 10 \text { th } \\
\text { day of } \\
\text { feeding }\end{array}$ & $\begin{array}{l}\text { On the 3rd day of } \\
\text { second hunger experi- } \\
\text { ment Yakriton (in } \mathrm{R} \text {. } \\
\text { A. U. per kilo of body } \\
\text { weight) subcutaneous- } \\
\text { ly used, } 5 \text { minutes } \\
\text { previous to the } \\
\text { ammonium injection }\end{array}$ \\
\hline $\begin{array}{l}\text { No. } 1 \text { (No. 1468) } \mathrm{Rf} \\
\text { No. } 2 \text { (No. 1500) Rf } \\
\text { No. } 3 \text { (No. 160S) Rf } \\
\text { No. } 4 \text { (No. 1600) Rf }\end{array}$ & $\begin{array}{l}b \\
b \\
b \\
b\end{array}$ & $\begin{array}{l}f \\
t \\
c \\
e\end{array}$ & $\begin{array}{l}f \\
i \\
f\end{array}$ & $\begin{array}{rl}\text { Li.t.l. } & \\
0 & f \text { (nexcentional) } \\
0 & r \\
30 & d \\
100 & e\end{array}$ \\
\hline
\end{tabular}

Remarks.

1. It may seem easy to determine by the above described method the injury through starvation on the first day, the second etc. of fasting until death occurs, but as the preparation of yakriton is very tedious for the time being, it is very difficult to make experiments especially with animals of class $b$ (as $\mathrm{R} b$ requires more yakriton than $\mathrm{R} f$ ), the actual figures of hunger injury will be reported in the future when an abundant supply of yakriton is available. In the present paper only the possibility of quantitative estimation of hunger injury has been described.

2 . If the above relation between the symptom of animals at the detoxicating liver test and the actual degradation of the detoxicating liver power is to be shown simply, it will be like the following diagram (see p. 270).

3. A chemical analogy to the above diagram may be mentioned here. Two very dilute chloride solutions are put each in a test tube, to which equal amounts of a silver nitrate solution are added. The resulting turbidity in each tube may resemble that in the other, but the precise quantitative determination may show that one solution is twice as much concentrated as the other. Turbidity may be compared with the symptom at the liver test (for instance, with convulsion within 15 minutes of the ammonium injection), while the actual amount of the silver combined with the chloride may be compared with the actual amount of yakriton needed to raise the animal to class $f$. 

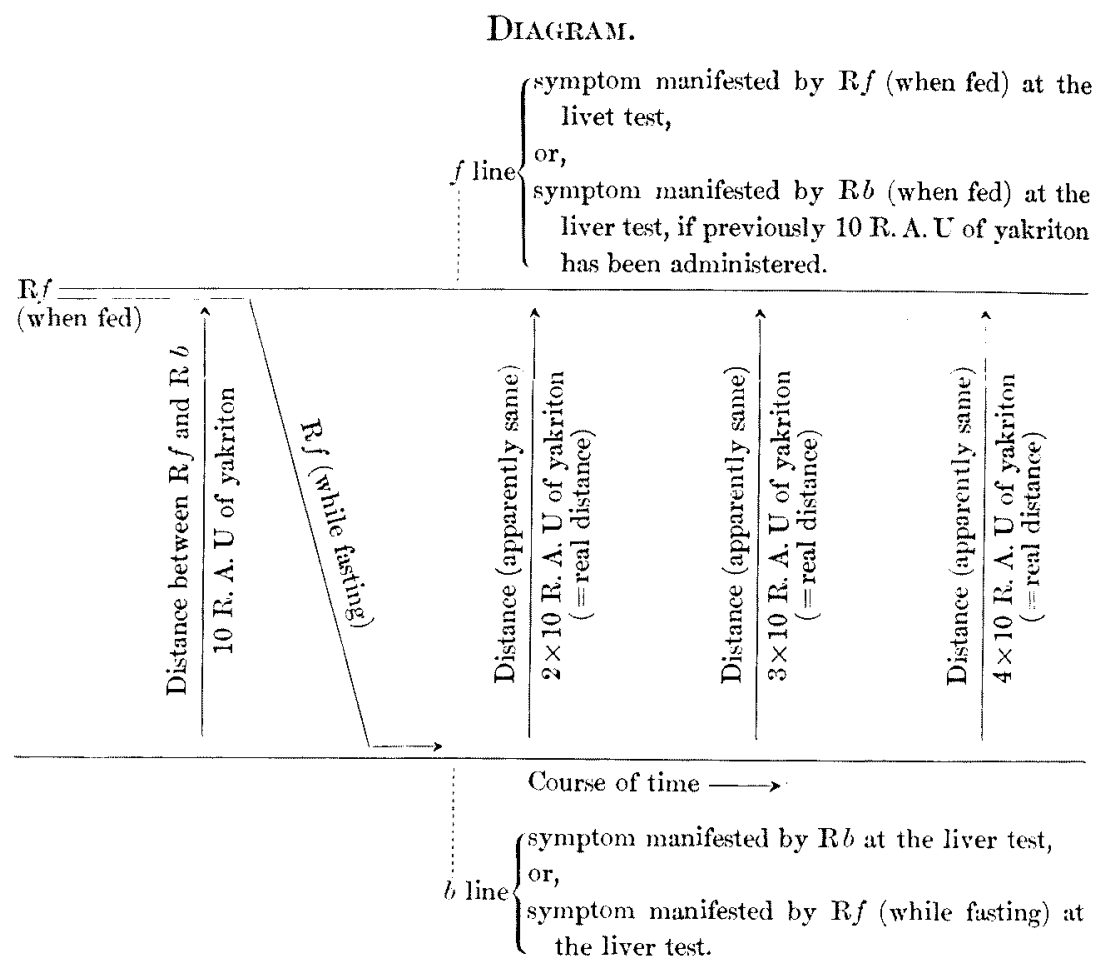

4. In the third report of these studies ${ }^{1)}$ it is mentioned that such a rabbit of ascending activity as $R b c d f$ is exceptional. Now it is clear that such a fresh animal, apparently healthy, had already been starved for some time previous to its arrival at our laboratory. It was not an exceptional animal, but was most probably an ordinary rabbit of class $f$ (when feeding) and was put to our liver test as soon as it arrived.

\section{Summary and Conclusions.}

1. To express the grade of hunger injury a scale is selected; it is the number of units of yakriton.

2. 10 R. A. U. (10 rabbit-ammonia-units) raises rabbits of class $b$ $(\mathrm{R} b)$ to those of class $f(\mathrm{R} f)$ provided they are both feeding. The distance between $\mathrm{R} b$ (=of ordinary detoxicating liver power) and $\mathrm{R} f$ (=of very active detoxicating liver power) may be defined as $10 \mathrm{R}$. A. U.

1) A. Sato and II. Sukurada, Tohoku J. Exp. Med., 1927, 8, 349. 
3. A $\mathrm{R} b$ remains, when it is made to fast, to be of class $b$, thus apparently to be of the same detoxicating power as when fed, but $10 \mathrm{R}$. A. $\mathrm{U}$. does not raise it to class $f$ any more, but many more units will be required according to the number of days of fasting. The distance between class $f$ and class $b$ has thus become much larger.

4. A $\mathrm{R} f$ becomes, when it is made to fast for some time, to be $\mathrm{R} b$, but then it remains $R b$. Thus it may seem that a $R f$ will, when made to fast, come down as far as $10 \mathrm{R}$. A. U. and stays there in spite of prolonged fasting. But now only many more units than $10 \mathrm{R}$. A. U. can raise it to the original class $f$ and the number of units is larger, the more the days of fasting.

5. Thus the hunger injury of an apparently healthy animal can be quantitatively determined if it is expressed in the number of units of yakriton. 